\title{
Newly Hatched Stage I American Lobster (Homarus americanus) Survival Following Exposure to Physically and Chemically Dispersed Crude Oil
}

\author{
Benjamin P. de Jourdan ${ }^{1}$ (1) $\cdot$ Tahereh Boloori $^{1}$. Les E. Burridge ${ }^{1}$
}

Received: 3 August 2021 / Accepted: 4 January 2022 / Published online: 27 January 2022

(c) The Author(s) 2022

\begin{abstract}
Standard model species are commonly used in toxicity tests due to their biological and technical advantages but studying native species increases the specificity and relevance of results generated for the potential risk assessment to an ecosystem. Accounting for intraspecies variability and other factors, such as chemical and physical characterization of test medium, is necessary to develop a reproducible bioassay for toxicity testing with native species. In this study, larval stage I American lobster (Homarus americanus), a commercially important and native species of Atlantic Canada, was used as the test species. Toxicity tests were first conducted by exposing lobster larvae to a reference toxicant of copper sulphate $\left(\mathrm{CuSO}_{4}\right)$ and then to physically and chemically (using Corexit 9500A) dispersed oil (WAF and CEWAF, respectively). The effect on larval survival was estimated by calculating the 24-h median effect concentration (24-h EC50), and there was no difference between WAF or CEWAF exposure when the results are reported on a total petroleum hydrocarbon (TPH) basis. The 24-h EC50s ranged from 2.54 to $9.73 \mathrm{mg}$ TPH/L when all trials $(n=19)$ are considered together. The HC5 (hazardous concentration for 5 per cent of the population) value was $2.52 \mathrm{mg} \mathrm{TPH} / \mathrm{L}$ and similar to the EC50 value when all trials were pooled. To evaluate the reproducibility of the lobster toxicity tests, inter-trial variability was determined, and the resultant coefficients of variation (\% CV) were compared to those reported for two standard test species, mysid shrimp (Americamysis bahia) and inland silverside (Menidia beryillina). This comparison showed that the \% CV for the lobster toxicity tests were lower than those for the standard species tests indicating that the described larval lobster toxicity bioassay produces reliable and repeatable results.
\end{abstract}

A common approach to minimize the impact of biological variability on the outcome of toxicity tests is to rely on laboratory cultures of standard test species, where a reduction, or exclusion, of genetic diversity serves to reduce experimental variability. The standard model species (e.g. Daphnia magna, Oncorhynchus mykiss, Danio rerio, Americamysis bahia, Menidia beryllina) generally meet certain technical criteria, such as easy and inexpensive maintenance in the laboratory, genetic tractability, and availability of a broad spectrum of experimental and methodological tools (Segner and Baumann 2015). These species also meet some biological criteria, such as fast growth, high reproductive potential, sensitivity to pollutants, abundance, replenishment ability, and/or captive rearing capabilities (Hughes et al. 2005).

Benjamin P. de Jourdan

Benjamin.deJourdan@huntsmanmarine.ca

1 Huntsman Marine Science Centre, Aquatic Biosciences, St. Andrews, NB, Canada
These practical and regulatory testing requirements of tests species have focused more research on testing a limited number of species to provide data from which comparison of relative toxicity of chemicals can be made. Extrapolations are also often made to predict the toxicological and ecological responses of other related species in the ecosystem. These extrapolations are typically based on descriptive or statistical relationships, such as uncertainty, safety, or assessment factors or interspecies correlation estimates (Bejarano and Barron 2014). The use of indigenous or native species, rather than a limited number of standard species, will increase the specificity and relevance of the data generated. However, there are often inherent problems working with these species, such as limited availability, lack of requisite information necessary for their acclimation and maintenance under laboratory conditions, and insufficient background information on their sensitivity and the reproducibility in toxicity testing (Echols et al. 2015). Regardless, as part of a Natural Resource Damage Assessment (NRDA), it is necessary to try and determine the effects of exposure on local, native 
species (Echols et al. 2015). This may be achieved by an aquatic toxicity programme that uses field collected and nonstandard test organisms of local relevance and importance. However, it is necessary to validate that the results gained from bioassays are precise and reproducible for these species to be successful in a toxicity programme. A possible significant factor contributing to the reproducibility may be the intraspecific variation that could contribute to either overor underestimating toxicity. Understanding the intraspecies variability and test precision of a proposed bioassay with a native species will allow the data to be properly interpreted and used for risk and damage assessments.

American lobster (Homarus americanus) is not a standard test species; however, due to its economic and ecological importance in eastern North America, it is prudent to characterize its risk from exposure to environmental contaminants, such as those associated with an oil spill. The first larval stages (I-III) of the American lobster are truly pelagic and considered to be more sensitive to contaminants and other stressors than the later benthic and adult stages (Burridge and Haya 1997). Hatching of larval lobsters occurs over a period of two or more months beginning in early to late June in the central and southern coastal Gulf of Maine, and about a month later in southern Nova Scotia and Browns Bank (Incze and Naimie 2000). The duration of the planktonic larval phase (stages I-III, and one postlarval stage, stage IV) is temperature dependent and may vary between laboratory reared and field organisms. Annis et al. (2007) reviewed and modelled larval development times for $H$. americanus and noted regional variations in field developmental times between the peak abundance of stage I and postlarvae, ranging from 12 days in the Gulf of Maine to up to 35 days off the Magdalen Islands (Gulf of St. Lawrence). These pelagic stages also represent the greatest potential for exposure to hydrocarbons associated with an oil spill and spill response measures (e.g. application of chemical dispersants), which tend to be more concentrated in surface waters.

The toxicological responses of American lobster exposed to petroleum hydrocarbons are less well understood compared to other crustaceans, such as the mysid shrimp (Americamysis bahia) a standard marine test organism. The sensitivity of pelagic lobster larvae (i.e. stages I-III) to crude oil has been previously demonstrated in laboratory studies (Wells and Sprague 1976) and as a result of accidental spills in the field (Reddy and Quinn 2001). The 1996 grounding of the North Cape barge off the southwestern coast of Rhode Island (USA) resulted in an estimated 2700 metric tons of fuel oil entering into the shallow near shore waters, killing approximately 9 million lobsters (French-McCay 2003).

Species sensitivity in response to a stressor may be variable due to experimental and natural parameters that need to be considered when investigating the impact of hazardous compounds to aquatic species. This data variability from laboratory-based toxicity tests introduces uncertainty when extrapolating for environmental risk assessment purposes. Thus, it is crucial to properly characterize the experimental and natural variabilities that may influence toxicity test results (Simmons et al. 2015). Mayer and Ellersieck (1986) demonstrated that physical conditions of the test environment, such as $\mathrm{pH}$ and temperature, and chemical properties of the test compound, such as solubility, can significantly influence toxicity test results. Biological variability proves more challenging to address as there are multiple contributing sources, including seasonal and temporal variation, genetic variation amongst individuals, and choice and life stage of test species (Hrovat et al. 2009; Simmons et al. 2015), differences in physiological status (e.g. size, age, sexual maturity status, etc.), and differential sensitivities of individuals to natural environmental parameters (Devin et al. 2014). Assessing the inter-individual variability of American lobster larvae is crucial for understanding its utility as a model test organism and understanding the risks to the population. Having more complete knowledge about the sensitivity of lobster larvae to petroleum hydrocarbons will also allow for a comparison with standard test species to better understand the relative sensitivity of this non-standard, commercially important species.

In the present study, we investigated the utility of American lobster larvae as a native test species in aquatic toxicology studies. Following method development and reference toxicant testing, the bioassay was used to assess the toxicity of petroleum hydrocarbons and the variability in response amongst different batches of larvae from the same lobster and between different lobsters. We hypothesized that there would not be a difference in response amongst larval batches from the same lobster, nor would there be differences between batches from different lobsters.

\section{Methods}

\section{Test Organism: American lobster (Homarus americanus)}

This study was undertaken using the first planktonic life stage (i.e. stage I) of the American lobster. Under a Fisheries and Oceans Canada special permit, adult commercial-size (0.5-2.0 kg) ovigerous ("berried") females were collected from the Bay of Fundy Lobster Fish Area 36 by local fishers. The lobsters $(n=30$, given sequential lobster IDs of $1-30)$ were transferred to the Huntsman Marine Science Centre (St. Andrews, NB) where they were held under controlled environmental conditions to promote egg mass development. Berried lobsters were transferred to an individual holding tank that received seawater of $18{ }^{\circ} \mathrm{C} \pm 2{ }^{\circ} \mathrm{C}$ when visual inspection of embryo development indicated that larval 
release was imminent. Larval lobsters released from each overnight hatch (termed a batch) were separately collected and held for single batch toxicity tests. Twenty lobster larvae were collected from each batch then imaged as reference organisms using a Leica Wild M420 microscope and Leica MD190 camera at $12.5 \times$ magnification. Carapace length (length from the rear of the orbital socket to the rear edge of the carapace) of reference lobster larvae was measured using the LAS software version 4.8. Weight and carapace length of berried female lobsters were also recorded to examine the role of maternal, morphological traits in explaining variability in response. A total of 14 of the collected 30 lobsters were utilized in this study.

\section{Exposure Methodology}

For American lobster, a classic breeding colony is not maintained as contributing adults are collected annually from new wild stock. The bioassay methodology was modified from previous internal studies performed at the Huntsman Marine Science Centre. Briefly, larval lobsters were collected from a single 24-h release from a single female lobster and transferred into an environmental chamber (temperature maintained at $15^{\circ} \mathrm{C} \pm 2{ }^{\circ} \mathrm{C}$ and a photoperiod of $16 \mathrm{~h} \mathrm{light}$ and $8 \mathrm{~h}$ dark). The transfer bucket was vigorously aerated to minimize cannibalism within the population. From the transfer bucket, a subsample of larvae was collected in a

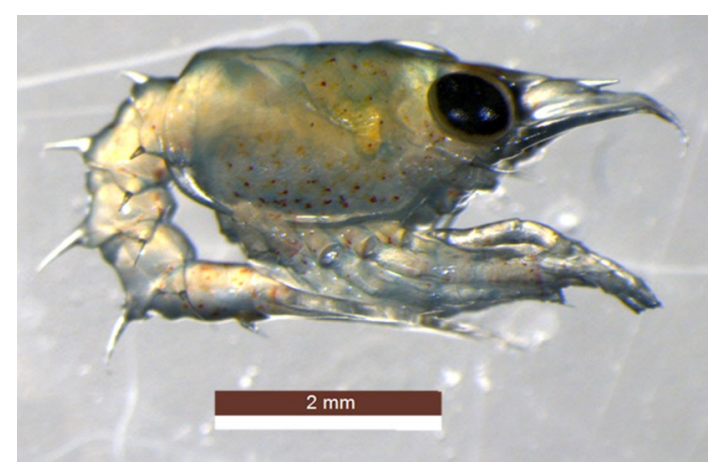

Fig. 1 Stage I larval lobster (Homarus americanus) at 24-h post hatching
$600 \mathrm{~mL}$ beaker and placed on a light table (A4 LED Light Box, FOME). An individual larva that was actively swimming in the water column was retrieved from the beaker using a transfer pipette modified to have a large, smooth opening and dispensed onto the corner of a folded KimWipe to remove excess water then visually confirmed to be stage I larvae as characterized by the absence of pleopods (Fig. 1).

The larva was gently transferred into a $25 \mathrm{~mL}$ scintillation vial filled with $20 \mathrm{~mL}$ of test media (allowing $20 \%$ headspace for surface oxygen exchange) using a metal scoopula and observed for $30 \mathrm{~s}$ to ensure larval viability and health before capping the vial (screwed tight, then loosened by a $1 / 4$ turn). There was no renewal of test solution during the exposure. The larvae were exposed with 1 individual per experimental unit to prevent cannibalism, with 10 replicate units per concentration. The larvae were observed during and after the exposure for $30 \mathrm{~s}$ and scored using the numeric categories described in Table 1.

Larvae were considered immobilized if they had a score of 2 or greater, and inline with other invertebrate methods, immobilization is considered here as a surrogate for death (USEPA 2016). Effect concentrations were calculated based on immobilization (EC50) and lethality (LC50) at 24 and/or $48 \mathrm{~h}$. Validity criteria for the toxicity tests included standard water quality-based measures (i.e. greater than $60 \%$ dissolved oxygen saturation and less than $1.5^{\circ} \mathrm{C}$ variation of temperature amongst treatment vials), as well as a species specific control survival criterion of less than $20 \%$ mortality, based on background studies and relatively high mortality rates for the species in an aquaculture environment (Sprague and McLeese 1968).

\section{Reference Toxicant Testing}

The availability of the larval lobster is seasonally limited (late summer, early fall). As such, there is only a short window of opportunity for toxicity testing, and a year-round reference toxicant testing programme is not feasible. Despite this limitation, the same reference toxicity testing principles were applied to the lobster larvae during their seasonal availability. Copper sulphate was selected as the reference

Table 1 Assessment endpoint scoring criteria for lobster larvae

\begin{tabular}{ll}
\hline Score & Description \\
\hline 0 & No observed effect: vigorously swimming, active internal organ movement \\
1 & Affected: passive swimming, erratic swimming, positioned on side or back, rigid body position, exopodites/pereiopod beating in coordi- \\
& nated motion \\
2 & Moribund (mortally affected): no swimming activity, twitching, sporadic movement of mouthparts and exopodites/pereiopod, positioned \\
& on side or back, faint heartbeat, slight internal organ movement \\
& Dead: no swimming, no visible heartbeat, change in coloration towards brown/opaqueness, absence of movement after gentle prodding \\
\hline
\end{tabular}


toxicant given its desirable traits (e.g. established toxicity database, readily available, water soluble, stable, easily analysed) and efficacy in providing a consistent and measurable effect in larval lobsters. A total of four reference toxicant tests were completed with concentrations of $0,3.3,10,33$, 100,330 , and $1000 \mu \mathrm{g} \mathrm{Cu} / \mathrm{mL}$, and larvae were scored at 24 and $48 \mathrm{~h}$.

\section{Preparation of WAF and CEWAF Stock Solutions}

Exposure waters were prepared in an environmental chamber $\left(15{ }^{\circ} \mathrm{C} \pm 2{ }^{\circ} \mathrm{C}\right)$ following a benchtop mixing method that modified the baffled flask method for dispersant effectiveness used by Environment Canada and the United States Environmental Protection Agency (Venosa et al. 2002) and the CROSERF method (Singer et al. 2000). Briefly, 1.6 L of $0.22 \mu \mathrm{m}$ filtered seawater from the Bay of Fundy was poured into a clean $2 \mathrm{~L}$ baffled flask. Water accommodated fractions (WAFs) were prepared by dispensing crude oil (artificially weathered by nitrogen stripping until $10 \%$ loss by mass) from offshore Newfoundland and Labrador onto the central surface of the water in the flask at a loading of $1 \mathrm{~g}$ oil/L of water. Chemically enhanced water accommodated fractions (CEWAFs) were prepared by adding Corexit 9500A to the centre of the surface oil slick at a dispersant to oil ratio of 1:20. The mixing flask was then sealed with DuraSeal, secured on an orbital shaker (MaxQ SHKE2000 digital shaker, Thermo Scientific), and shaken at $150 \mathrm{rpm}$ for $1 \mathrm{~h}$ before allowed to settle for $1 \mathrm{~h}$. This mixing method was calibrated to mimic droplet size and distribution results obtained from a wave tank study conducted by SL Ross (Ottawa, ON) that served as a proxy for offshore Newfoundland and Labrador conditions. These stock solutions were then diluted to generate exposure media. A dispersant only control was prepared at a concentration that was equal to the volume of dispersant in the highest tested CEWAF concentration and was nominally $15.8 \mathrm{mg} / \mathrm{L}$ in the range finding test (equal to the highest CEWAF concentration tested, 32\%) and $4.75 \mathrm{mg} / \mathrm{L}$ in the definitive tests (equal to the highest CEWAF concentration test, $10 \%$ ).

\section{Acute Toxicity Test with WAF and CEWAF}

A total of 19 toxicity tests were conducted between June and September 2018 using 14 female lobsters (see SI Table 1 for additional details). The toxicity tests were conducted in the same manner as described for the reference toxicant testing, with a 24-h exposure duration. The dilution water for toxicity tests was the same filtered seawater that was used to prepare WAF and CEWAF stock solutions. The preliminary range finding trials included test solutions of $100 \%, 56 \%$, $32 \%, 18 \%$, and $10 \%$ of WAF stock solution and $32 \%, 18 \%$, $10 \%, 5.6 \%$, and $3.2 \%$ of CEWAF stock solution, as well as a dispersant only control $(15.8 \mathrm{mg} / \mathrm{L})$ and a seawater control. The definitive toxicity tests followed with nominal concentrations of $100 \%, 56 \%$ and $32 \% \mathrm{WAF}$ and $10 \%, 3.2 \%$ and $1 \%$ CEWAF stock solutions, along with the dispersant only control $(4.75 \mathrm{mg} / \mathrm{L})$ and seawater control, each tested with 10 organisms per treatment. A randomized experimental setup was employed, and treatments were blinded to assessors to eliminate potential bias.

\section{Exposure Media Characterization}

Water quality parameters were measured in three replicates per test solution pre- and post-exposure. Dissolved oxygen (DO\%) and temperature $\left({ }^{\circ} \mathrm{C}\right)$ were measured using a YSI model ProSolo Digital Water Quality Meter (Yellow Springs Instruments, Yellow Springs, OH, USA). Salinity (psu) and pH were measured using the YSI model MultiLab 4010-2 (Yellow Springs Instruments, Yellow Springs, OH, USA) calibrated with standard $\mathrm{pH}$ buffer solutions.

Samples of each test solution from a single trial were collected at the beginning of the study and sent to a contract laboratory (RPC, Fredericton, New Brunswick) for characterization of total petroleum hydrocarbons (TPH), polycyclic aromatic hydrocarbons (PAHs) and alkyl-PAHs by GC-MS based on the method described in the USEPA 3510C/8270C document (Edgell and Wesselman 1989).

A LISST-100X particle size analyzer (Sequoia Scientific, Inc) was used to characterize the mean droplet concentration value per bin class $(\mathrm{VC}, \mu \mathrm{L} / \mathrm{L}$ ), the particle size distribution, and the mean droplet size calculated from 60 independent measurements of each test solution of every WAF and CEWAF preparation. The concentrations of TPH for the CEWAF were estimated in the rest of the experimental trials based on the regression relationship between VC and TPH. The measured concentrations were used to model immobilization response and determine the effect concentration to $50 \%$ of the population (i.e. EC50).

\section{Statistical Design and Data Analysis}

Water quality parameters, carapace length of reference lobsters, and the wet weight of female lobsters were all tested for normality and homogeneity of variance using Shapiro-Wilk and Levene's tests, respectively. Analysis of variance (ANOVA) using R program was performed to investigate any significant differences within and between datasets. The significance criterion was set at $p<0.05$. In cases with significant differences, the post hoc Tukey test was performed to find the trial(s) with significantly different effect concentration(s). If the assumptions of normality and homogeneity of variance were not met, then the nonparametric test of Mann-Whitney U (also called Wilcoxon Rank Sum Test) was performed. 
The $d r c$ package (v 3.0-1; Ritz et al. 2015) in R (v 3.6.1; $\mathrm{R}$ Core Team 2019) was used to fit the appropriate model to the acute toxicity results. The best-fit model with the smallest Akaike information criterion (AIC) value was selected to represent the concentration-response curve for each experimental trial and used to calculate the 24-h EC50s for the WAF and CEWAF exposures, and a 48-h EC50 for the reference toxicity testing. The variability in the toxic responses of larval lobsters was assessed as a function of maternal origin. In cases where a single female produced more than one batch of larvae, the responses of individual batches were compared to one another. In addition, the responses of larvae from different females were compared across trials. The precision of acute toxicity results for both within and amongst females was evaluated using the coefficient of variation (CV) and standard deviation.

A species sensitivity distribution (SSD) type approach was used with the cumulative distribution of EC50 values to assess the potential risk to the lobster larvae population. A log-normal distribution function and resampled randomly 1000 times were used to generate the SSD mean value and the $5^{\text {th }}$ percentile hazard concentration (HC5) with corresponding $95 \%$ confidence interval $(95 \% \mathrm{CI})$.

The reference toxicant results were compared with literature values curated from the US Environmental Protection Agency ECOTOX database (USEPA, 2019) to assess how the results from this bioassay are compared to previously published values for lobster and other marine crustaceans. To compare the consistency of results and the variability of the bioassay, the CV was determined for the LC50 results $(n=19)$ determined in this study and was compared to the CV from 91 data points obtained from the USEPA National Contingency Plan (NCP) Product Schedule (USEPA 2021) showing the toxicity of No. 2 Fuel oil as 48-h EC50 (mysid shrimp) and 96-h LC50 (inland silverside) on a TPH basis.

\section{Results}

\section{Reference Toxicant Testing}

The 48-h EC50 values ranged from 105.4 to $151.1 \mu \mathrm{g} / \mathrm{L}$, with a CV of $15.9 \%$. The 48 -h LC50 values align with those from the literature (100-330 $\mu \mathrm{g} / \mathrm{L}$, Connor 1972) for larval lobster (Homarus gammarus) and the resulting high degree of precision supports the use of this bioassay to study the effects of other contaminants.

\section{Exposure Media Characterization}

\section{Water Quality}

No significant differences were observed for temperature, salinity, or $\mathrm{pH}$ between experimental trials at both pre- and post-toxicity measurements. The DO (\% saturation) in control seawater was significantly different from the $1(p=0.04)$ and 3.2\% ( $p=0.01)$ CEWAF treatments across all trials in the post-exposure measurements. The mean value of DO declined from $93.9 \%( \pm 2.3 \%)$ to $83.3 \%( \pm 8.5 \%)$ across all trials between pre- and post-exposure but never dropped below $60 \%$ saturation. Salinity values followed ambient conditions and ranged from 29 to 32 PSU over the course of the study. $\mathrm{pH}$ ranged between 7.33 and $7.90($ mean $=7.76)$ in the pre-exposure solutions and 6.78-7.94 (mean $=7.75)$ in the post-exposure solutions. The variability of temperature in the test solutions was not significantly different between the two measurements with an average temperature of $14.4{ }^{\circ} \mathrm{C}$ $\left( \pm 0.6{ }^{\circ} \mathrm{C}\right)$ and $14.5{ }^{\circ} \mathrm{C}\left( \pm 0.5{ }^{\circ} \mathrm{C}\right)$ at the pre- and postexposure measurements, respectively. The mean, standard deviation and the coefficient of variation $(\mathrm{CV}$; measure of inter-trial variability) of the water quality parameters across all trials $(n=19)$ are shown in Supplemental Information Table 2.

\section{Chemical Characterization}

The chemical characterization of the TPH analytes for the WAF and CEWAF treatments is shown in Table 2.

\section{Physical Characterization}

The concentrations of each analyte increased as the nominal concentration of the chemically dispersed oil elevated (i.e. 1\%, 3.2\% and 10\%). The measured concentrations of TPH analytes were below the method detection limit (MDL) of the GC-MS in the control seawater and dispersant only control.

In the WAF samples, the LISST transmissivity was too great $(>85 \%)$ resulting in an unreliable reading and an instrument warning that the sample was "too clear". As such, only the results from the CEWAF solutions are presented. The volume concentration (VC) in each bin increased with increasing strength of test solution and was linearly correlated with increase in TPH concentration. There was very good consistency between preparations in terms of droplet profile and concentrations. The mean droplet size from the nine different preparations of 3.2\% CEWAF ranged from 3.9 to $10.8 \mu \mathrm{m}$ with a mean value of 6.3 (standard deviation $=2.4)($ SI Fig. 1).

\section{Bioassay}

A total of 19 bioassays were performed using American lobster larvae from 14 individual berried females. There were significant differences observed between the carapace length $(\mathrm{mm})$ of lobster larvae from different batches and/or different females $(p<0.05)$. The carapace length of reference 
Table 2 Concentration (mg/L) of the total petroleum hydrocarbon (TPH) of nominal concentrations of physically dispersed oil (32\% WAF) and chemically enhanced fraction of oil (1\%, 3.2\% and 10\% CEWAF) dispersed using Corexit 9500A

\begin{tabular}{|c|c|c|c|c|c|c|c|}
\hline Analytes & MDL & Control seawater & $\begin{array}{l}\text { Corexit 9500A Control } \\
\text { (nominal } 4.75 \mathrm{mg} / \mathrm{L} \text { ) }\end{array}$ & $32 \% \mathrm{WAF}$ & $1.0 \%$ CEWAF & $3.2 \%$ CEWAF & $10 \%$ CEWAF \\
\hline Benzene & 0.001 & $<\mathrm{MDL}$ & $<\mathrm{MDL}$ & 0.015 & 0.0005 & 0.001 & 0.004 \\
\hline Toluene & 0.001 & $<\mathrm{MDL}$ & $<\mathrm{MDL}$ & 0.31 & 0.01 & 0.03 & 0.12 \\
\hline Ethylbenzene & 0.001 & $<\mathrm{MDL}$ & $<\mathrm{MDL}$ & 0.06 & 0.003 & 0.009 & 0.034 \\
\hline Xylenes & 0.001 & $<\mathrm{MDL}$ & $<\mathrm{MDL}$ & 0.3 & 0.015 & 0.049 & 0.18 \\
\hline VPH C6-C10 (Less BTEX) & 0.01 & $<\mathrm{MDL}$ & $<\mathrm{MDL}$ & 0.52 & 0.05 & 0.14 & 0.45 \\
\hline $\mathrm{EPH}>\mathrm{C} 10-\mathrm{C} 16$ & 0.05 & $<\mathrm{MDL}$ & $<\mathrm{MDL}$ & 0.33 & 0.49 & 1.6 & 5.1 \\
\hline $\mathrm{EPH}>\mathrm{C} 16-\mathrm{C} 21$ & 0.05 & $<\mathrm{MDL}$ & $<\mathrm{MDL}$ & 0.07 & 0.4 & 1.3 & 3.8 \\
\hline $\mathrm{EPH}>\mathrm{C} 21-\mathrm{C} 32$ & 0.1 & $<\mathrm{MDL}$ & $<\mathrm{MDL}$ & $<\mathrm{MDL}$ & 0.06 & 1.8 & 5.8 \\
\hline Modified TPH Tier 1 & 0.1 & $<\mathrm{MDL}$ & $<\mathrm{MDL}$ & 0.9 & 1.5 & 4.8 & 15.0 \\
\hline TPH & & 0.00 & 0.00 & 1.61 & 1.57 & 4.93 & 15.49 \\
\hline
\end{tabular}

*MDL Method detection limit

Values $\leq$ MDL were replaced with $\frac{1}{2}$ MDL for calculating sums

larvae ranged from 1.74 to $2.21 \mathrm{~mm}$ with the average length of $1.99 \mathrm{~mm}( \pm 0.087 \mathrm{~mm}, n=380)$ and increased linearly with increasing adult lobster wet weight (SI Fig. 2).

Immobilization was assessed in each individual larvae following the 24-h exposure. The performance of lobster larvae in the control seawater and the dispersant only control met the validity criteria of less than $20 \%$ mortality/immobilization in all the trials. The control and dispersant only control treatments each showed a very consistent lack of immobilization response across all trials. The results from each trial are visually summarized in the Supplemental Information (SI Fig. 3). The immobilization data from each batch were separately fit against the TPH concentration for each the WAF and CEWAF exposures, as well as combining the responses for each exposure type. Comparing the best fitted model for the TPH-based effective concentration for different experimental trials supported the Weibull1.3 model as the best fitted model in most cases (Table 3). The best fitted model was then used to calculate the EC50 values and $95 \%$ confidence intervals.

The TPH-based 24-h EC50 values ranged from 2.30 to $4.77 \mathrm{mg} / \mathrm{L}$ for the WAF exposures, $2.15-12.8 \mathrm{mg} / \mathrm{L}$ for the CEWAF exposures, and 2.54-9.73 $\mathrm{mg} / \mathrm{L}$ when the exposures were considered together. In each case, the least sensitive batch was the third release from female 25 . The most sensitive batch was the first release from female 15 when considering the CEWAF-only exposure, but the third release from female 4 when considering the WAF only and the combined data. There were few differences between the EC50 estimates from a given batch regardless of the method of calculating the effect concentration. This was also seen when the data from all trials were pooled and analysed based on WAF and CEWAF exposures alone and combined (Fig. 2). The EC50 values calculated from the combined responses
(Table 3) were used to generate a cumulative distribution from which an HC5 equal to $2.52 \mathrm{mg} / \mathrm{L}$ was calculated for exposure to hydrocarbons for larval lobsters (Fig. 3).

\section{Variability}

The inter-trial variability between the immobilization response of lobster larvae to the total petroleum hydrocarbons was assessed using EC50 values from the combined responses. The coefficient of variation $(\mathrm{CV})$ between all trials was $37 \%$, while that within lobster CV was $23.3 \%$ as determined from lobster 16 which had three batches tested, with no significant $(p>0.05)$ difference in response between successive larval batches. The inter-trial variability of the 24-h EC50 values was compared with the acute toxicity of standard test species of mysid shrimp (Americamysis bahia) and inland silversides (Menidia beryllina) obtained from the US EPA NCP Product Schedule (US EPA 2019). The coefficient of variation was 216.7 and $198.9 \%$ for mysid shrimp and inland silverside, respectively (Fig. 4).

\section{Discussion}

The use of reference toxicants allows researchers to provide a measure of precision and proficiency. The use of larval lobsters presents a challenge for a standard reference toxicant quality monitoring programme due to their seasonal availability. However, it is still possible to include reference toxicant testing within a toxicology programme, even if only for a limited season. Our results demonstrated that the bioassay was sensitive, repeatable, and precise, as the achieved LC50 values for copper sulphate align well with what has previously been observed. The results from the reference 
Table 3 The best fitted model based on the AIC criterion and calculated 24-h EC50 values $(\mathrm{mg} / \mathrm{L})$ with lower and upper limits (95\% confidence limits) calculated on the basis of WAF and CEWAF alone and combined. The lowest EC50 value in each column is bolded and the highest values are bold and italicized

\begin{tabular}{|c|c|c|c|c|c|c|c|}
\hline \multirow[t]{2}{*}{ Lobster ID } & \multirow[t]{2}{*}{ Batch } & \multicolumn{2}{|l|}{ WAF } & \multicolumn{2}{|c|}{ CEWAF } & \multicolumn{2}{|c|}{ Combined } \\
\hline & & Model & $\begin{array}{l}\text { 24-h EC50 (95\% } \\
\text { CI) (TPH mg/L) }\end{array}$ & Model & $\begin{array}{l}\text { 24-h EC50 (95\% } \\
\text { CI) (TPH mg/L) }\end{array}$ & Model & $\begin{array}{l}\text { 24-h EC50 (95\% } \\
\text { CI) (TPH mg/L) }\end{array}$ \\
\hline \multirow[t]{2}{*}{2} & 1 & W2.3 & $3.60(2.60-4.61)$ & $\mathrm{W} 1.3$ & $4.71(4.71-4.71)$ & LL.4 & $4.72(4.49-4.95)$ \\
\hline & 2 & W1.3 & $2.93(2.91-2.94)$ & W1.3 & $2.28(2.26-2.31)$ & W1.3 & $2.91(2.56-3.26)$ \\
\hline 3 & 1 & W1.4 & $4.07(3.87-4.27)$ & W1.3 & $3.24(3.15-3.33)$ & W1.3 & $4.08(4.07-4.10)$ \\
\hline 4 & 3 & W1.3 & $\mathbf{2 . 3 0}(2.21-2.40)$ & W1.3 & $5.46(4.98-5.94)$ & W1.3 & $\mathbf{2 . 5 4}(-6.47-11.56)$ \\
\hline 6 & 1 & W1.3 & $3.35(3.07-3.64)$ & W1.3 & $3.10(3.02-3.19)$ & W1.3 & $5.35(1.90-8.79)$ \\
\hline 8 & 1 & W1.3 & $2.81(2.80-2.81)$ & W1.3 & $5.33(5.33-5.33)$ & W1.3 & $4.54(2.94-6.13)$ \\
\hline \multirow[t]{2}{*}{9} & 1 & W1.3 & $2.83(2.82-2.84)$ & W1.3 & $3.44(3.44-3.44)$ & W1.3 & $3.19(2.68-3.70)$ \\
\hline & 2 & LL.4 & $3.15(2.89-3.41)$ & LL.4 & $4.53(0.30-8.75)$ & LL.4 & $3.10(1.36-4.85)$ \\
\hline 15 & 1 & W1.3 & $3.93(3.93-3.94)$ & W1.4 & $\mathbf{2 . 1 5}(2.15-2.15)$ & W1.3 & $3.90(2.30-5.50)$ \\
\hline \multirow[t]{3}{*}{16} & 1 & W1.3 & $4.09(3.05-5.12)$ & W2.3 & 8.98(6.10-11.86) & W1.3 & $4.79(1.20-8.39)$ \\
\hline & 2 & W1.3 & $2.93(2.91-2.94)$ & W1.3 & $6.07(6.02-6.12)$ & W1.3 & $3.69(1.02-6.37)$ \\
\hline & 3 & W1.3 & $2.46(2.37-2.54)$ & W1.3 & $7.84(7.84-7.85)$ & W1.3 & $5.93(3.02-8.84)$ \\
\hline 17 & 1 & W2.4 & $2.84(0.33-5.36)$ & W1.3 & $5.33(5.33-5.33)$ & W1.3 & $3.52(1.38-5.66)$ \\
\hline \multirow[t]{2}{*}{18} & 1 & W1.3 & $2.58(2.52-2.62)$ & W1.3 & $8.06(6.91-9.20)$ & W1.3 & $4.77(-1.09-10.63)$ \\
\hline & 2 & W1.3 & $3.45(3.17-3.73)$ & W1.3 & $7.33(7.15-7.51)$ & W1.3 & $3.03(1.60-4.46)$ \\
\hline 19 & 1 & LL.4 & $3.04(2.99-3.08)$ & LL.4 & $4.37(4.37-4.37)$ & W1.3 & $3.15(-3.25-9.55)$ \\
\hline 21 & 1 & LL.4 & $3.86(3.23-4.50)$ & W1.3 & $5.41(3.51-5.31)$ & W1.3 & $3.38(-21.29-28.05)$ \\
\hline 22 & 1 & W1.4 & $4.07(3.87-4.27)$ & W1.4 & $9.54 * *(9.50-9.58)$ & W1.3 & $4.99(4.99-5.00)$ \\
\hline 25 & 3 & W2.3 & $4.77 *(3.80-5.73)$ & LL.4 & $12.85(6.46-19.25)$ & LL.4 & 9.73(-1.16-20.62) \\
\hline
\end{tabular}

$L L$ Log-logistic, W1 Type 1 weibull, W2 Type 2 weibull

*Significant difference between $24 \mathrm{~h}$ EC50 value of WAF with CEWAF and Combined $(p<0.05$

**Significant difference between $24 \mathrm{~h}$ EC50 value of CEWAF with WAF and Combined $(p<0.05)$
Fig. 2 Concentration immobilization response models considering the WAF (blue triangles), CEWAF (red circles), and combined (black line) data. The dashed vertical lines are the EC50 values, which are reported in the inset

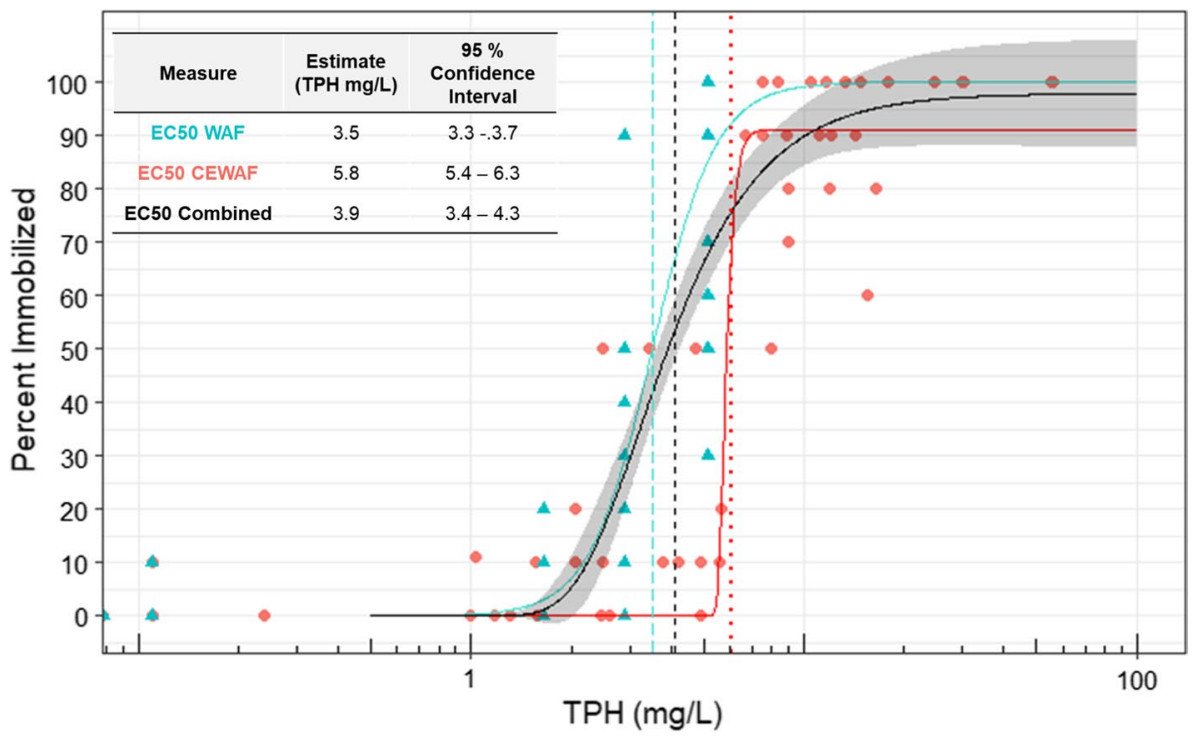

toxicant testing highlight that the data generated under these testing conditions are reflective of legitimate sensitivity and not an artefact of poor testing conditions, organism health, or handling stress. Based on a curated dataset from the USEPA ECOTOX database (2019), the 48-h LC50 derived in this study places the lobster from this bioassay in the lower 35 th percentile of larval marine crustaceans for copper sensitivity (Supplemental Information, Table 3).

Two aspects should be identified to account for the variability of species sensitivity in ecotoxicology: the potential causes of the variability and the significance of those variabilities (Calow 1996). In this study, a consistent 

toxicity values where each point is an individual batch (lobster ID - release number). The horizontal, dotted, red line is the the vertical dashed black line is the pooled EC50 estimate of $3.9 \mathrm{mg} / \mathrm{L}$
Fig. 3 Distribution of lobster $\mathrm{HC} 5$ estimate of $2.5 \mathrm{mg} / \mathrm{L}$ and

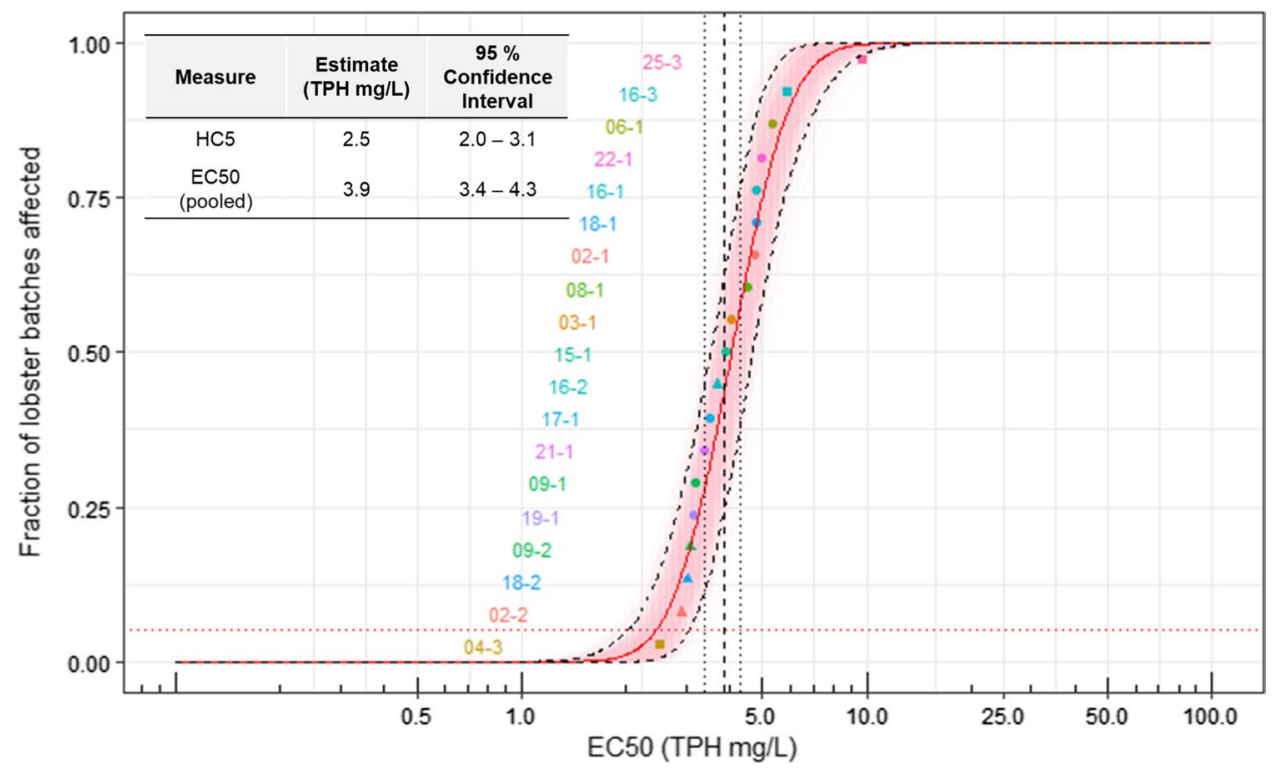

Fig. 4 Comparing the variability of $24 \mathrm{~h}$ EC50 of American lobster larvae (Homarus americanus) $(n=19)$ exposed to offshore crude oil with the 48-h EC50 of mysid shrimp (Americamysis bahia) $(n=91)$ and 96-h LC50 of inland silversides (Menidia beryllina) $(n=91)$ exposed to No. 2 Fuel Oil (data collected from USEPA NCP Schedule J listings)

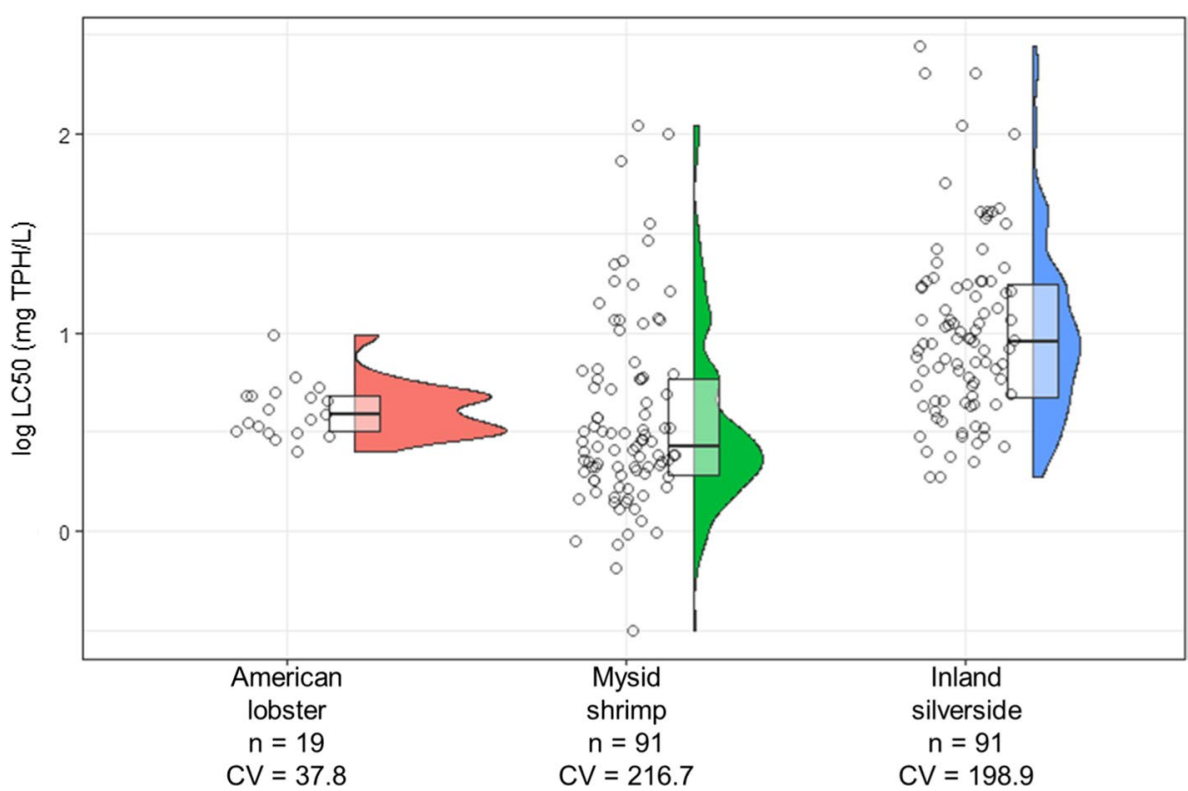

methodology was followed to limit the number of variables that may contribute to variability in response. For example, the water quality parameters in the test solutions are considered as potential causes of experimental variabilities (Hrovat et al. 2009), and in this study, water quality parameters were consistent across all trials. Therefore, any variability in response observed in this study would be attributable to biological factors.

Lack of variation in sensitivity of early life stages of lobster to acute exposure of oil may be attributed to narcotic mechanism of action of oil products that is not taxa specific (Barron et al. 2004; Russom et al. 1997). The relatively low variability in the toxic response of lobster larvae might be due to reduced variation in the ability of crustacea to metabolize xenobiotics. There is no consensus on the presence and inducibility of cytochrome 1A (CYP1A) enzymes in invertebrates (Koening et al. 2012). James and Boyle (1998) reviewed cytochrome P450 in crustacea and found evidence that lobsters (Panulirus argus and H. americanus) do not perform biotransformation of benzo-a-pyrene $(\mathrm{B}[\mathrm{a}]$ $\mathrm{P}$ ) in a CYP1A-dependent manner. Most remaining $\mathrm{B}[\mathrm{a}] \mathrm{P}$ was untransformed accumulating in the muscle and hepatopancreas of the American lobster. The authors also noted that the aryl hydrocarbon receptor (AhR) is absent in American lobster. Altogether, it suggests that the lobster does not have the same ability to metabolize and ameliorate exposure to petroleum hydrocarbons as do fish or mammals. The absence, or reduced capacity, for xenobiotic metabolism is 
compounded by the potentially relatively low level of genetic variability in lobsters, which limits the ability for selection and adaptation. Tracey et al. (1975) employed starch-gel electrophoresis followed by a selective enzyme assay to quantify the amount of genetic variation in geographically distinct (three offshore and five nearshore) natural populations of the American lobster. They found there to be rather low levels of genetic variability within the 300 animals surveyed, with the average proportion of heterozygous loci per individual being $3.8 \%$. The small and nearly constant variance in EC50 values observed for lobsters in this study may be indicative of low phenotypic variability, which can be associated with lower genetic variability (Devin et al. 2014), and may be a reflection of the fact that these wild lobsters all had been caught within the same area (Lobster Fishing Area 36) and are of unknown relatedness. The significance of low variability in terms of sensitivity to hydrocarbons observed in this study may speak to a reduced resilience within this population and a reduced pool of survivors to repatriate following an oil spill.

The procedure used to prepare the exposure medium for toxicity tests can alter the sensitivity of test species to the oil/dispersed oil, irrespective of type of dispersant or oil product. Therefore, determining the concentration of oil constituents is required to account for the subsequent variability in the observed toxic responses, and not just a nominal reporting of dilution. In the current study, combining the WAF and CEWAF exposures along the measured concentration continuum exhibited nearly equal precision when estimating the oil toxicity to lobster larvae than when the WAF and CEWAF were considered alone. The CV of the EC50 values calculated from the combined WAF and CEWAF was equal to $37.8 \%$ as compared with the WAF and CEWAF alone with CVs of $20.3 \%$ and $47.5 \%$, respectively.

Previous studies have set acceptable ranges for intraand inter-laboratory variability based on the $\mathrm{CV}$, corresponding to excellent $(\mathrm{CV}<35 \%)$, good $(35-60 \%)$, and unacceptable ( $>86 \%$ ) (Echols et al. 2015). The precision in this study puts the larval lobster bioassay in the 'good' category and strengthens the reliability of the results. The 24-h LC50 values from this study are in the low $\mathrm{mg} / \mathrm{L} \mathrm{TPH}$ range $($ mean $=4.2 \mathrm{mg} / \mathrm{L}$ ), which is consistent with those obtained using the standard test species mysid shrimp (mean $=21.2 \mathrm{mg} / \mathrm{L}$, Fig. 4). The lobster and mysid studies were conducted under different conditions, with different oils, and different durations, and as such a direct comparison is not appropriate. However, the results highlight that the lobster bioassay presented here has similar desirable traits of sensitivity and reproducibility that make it a viable option when there is a desired to perform toxicity testing with local species, such as in a risk or damage assessment.

The difference between the pooled LC50 (3.9 mg/L $\mathrm{TPH})$ and the HC5 $(2.5 \mathrm{mg} / \mathrm{L} \mathrm{TPH})$ is quite narrow and reflects that an increase in concentration above the HC5 will quickly translate into significant effects. When considering these values for risk assessment, application factors (e.g. 10) could be applied to the HC5 estimate to add a larger degree of conservatism; however, the exposure conditions in this study (static, non-renewal, 24-h duration) likely overestimate the real-world dynamic exposure scenario following an oil spill and thus may provide sufficient conservatism. These results demonstrate that the larval lobster bioassay is sensitive, reliable and may be successfully implemented to assess the hazard from marine contaminants. Application of this bioassay to test the hazard of physically and chemically dispersed crude oil revealed that lobster larvae are sensitive to petroleum hydrocarbon exposure and as a population they exhibit limited variability in response. These observations may place them at greater risk of extirpation should a severe oil spill occur during the same seasonal window when stage I lobster larvae are present.

Supplementary Information The online version contains supplementary material available at https://doi.org/10.1007/s00244-022-00912-z.

Acknowledgements The co-authors would like to thank the three anonymous reviewers for taking their time to review our manuscript and provide helpful comments that contributed to the improvement of this manuscript. We also acknowledge the Huntsman Marine Science Centre staff for their dedicated work in supporting and conducting the experiments reported in this study including E. Dowling, R. Eldridge, E. Fanning, D. Goodwin, E. Harvey, T. Hurley and A. McCarthy. Additional funding was provided by the Government of Canada's Department of Fisheries and Oceans Multi-Partner Research Initiative.

Funding Funding for this work was provided through The Environmental Studies Research Fund, ESRF 2014-04S.

Data Availability Upon request.

Code Availability Upon request.

\section{Declarations}

Conflict of interest The authors declare that they have no conflict of interest.

Open Access This article is licensed under a Creative Commons Attribution 4.0 International License, which permits use, sharing, adaptation, distribution and reproduction in any medium or format, as long as you give appropriate credit to the original author(s) and the source, provide a link to the Creative Commons licence, and indicate if changes were made. The images or other third party material in this article are included in the article's Creative Commons licence, unless indicated otherwise in a credit line to the material. If material is not included in the article's Creative Commons licence and your intended use is not permitted by statutory regulation or exceeds the permitted use, you will need to obtain permission directly from the copyright holder. To view a copy of this licence, visit http://creativecommons.org/licenses/by/4.0/. 


\section{References}

Annis ER, Incze LS, Wolff N, Steneck RS (2007) Estimates of in situ larval development time for the lobster, Homarus americanus. J Crust Biol 27:454-462. https://doi.org/10.1651/S-2758.1

Barron MG, Carls MG, Heintz R, Rice SD (2004) Evaluation of fish early life-stage toxicity models of chronic embryonic exposures to complex polycyclic aromatic hydrocarbon mixtures. Toxicol Sci 78:60-67. https://doi.org/10.1093/toxsci/kfh051

Bejarano AC, Barron MG (2014) Development and practical application of petroleum and dispersant interspecies correlation models for aquatic species. Environ Sci Technol 48:4564-4572. https:// doi.org/10.1021/es500649v

Burridge LE, Haya K (1997) Lethality of pyrethrins to larvae and postlarvae of the American lobster (Homarus americanus). Ecotoxicol Environ Saf 38:150-154. https://doi.org/10.1006/eesa.1997.1571

Calow P (1996) Variability: noise or information in ecotoxicology? Environ Toxicol Pharmacol 2:121-123. https://doi.org/10.1016/ S1382-6689(96)00041-5

Connor PM (1972) Acute toxicity of heavy metals to some marine larvae. Mar Pollut Bull 3:190-192. https://doi.org/10.1016/0025326X(72)90268-8

Devin S, Giamberini L, Pain-Devin S (2014) Variation in variance means more than mean variations: what does variability tell us about population health status? Environ Int 73:282-287. https:// doi.org/10.1016/j.envint.2014.08.002

Echols BS, Smith AJ, Rand GM, Seda BC (2015) Factors affecting toxicity test endpoints in sensitive life stages of native Gulf of Mexico species. Arch Environ Contam Toxicol 68:655-662. https://doi. org/10.1007/s00244-014-0122-7

Edgell K, Wesselman R (1989) USEPA (Environmental Protection Agency) method study 36 SW-846 methods 8270/3510, GC/MS (gas chromatography/mass spectrometry) method for semivolatile organics: capillary-column technique separatory-funnel liquidliquid extraction. Final report, September 1986-December 1987

French-McCay D (2003) Development and application of damage assessment modeling: example assessment for the North Cape oil spill. Mar Pollut Bull 47:341-359. https://doi.org/10.1016/ S0025-326X(03)00208-X

Hrovat M, Segner H, Jeram S (2009) Variability of in vivo fish acute toxicity data. Regul Toxicol Pharmacol 54:294-300. https://doi. org/10.1016/j.yrtph.2009.05.013

Hughes R, Reichelt-Brushett AJ, Newman L (2005) Identifying suitable invertebrate species from a unique habitat for ecotoxicological testing. Australas J Ecotoxicol 11:85-92

Incze LS, Naimie CE (2000) Modelling the transport of lobster (Homarus americanus) larvae and postlarvae in the Gulf of Maine. Fish Oceanogr 9:99-113. https://doi.org/10.1046/j.13652419.2000.00125.x

James MO, Boyle SM (1998) Cytochromes P450 in crustacea. Comp. Biochem Physiol - C Pharmacol Toxicol Endocrinol 121:157-172. https://doi.org/10.1016/S0742-8413(98)10036-1

Koening S, Fernández P, Solé M (2012) Differences in cytochrome P450 enzyme activities between fish and crustacea: Relationship with the bioaccumulation patterns of polychlorobiphenyls (PCBs). Aquat Toxicol 108:11-17. https://doi.org/10.1016/j.aquatox.2011. 10.016
Mayer, F.L., 1986. Manual of acute toxicity: Interpretation and data base for 410 chemicals and 66 species of freshwater animals. Fish and Wildlife Service Resource Publication no. 160. U.S. Department of Interior, Washington, D.C. $581 \mathrm{pp}$.

R Core Team (2019) R: A language and environment for statistical computing. R Foundation for Statistical Computing, Vienna, Austria. https://www.R-project.org/

Reddy CM, Quinn JG (2001) The North Cape oil spill: hydrocarbons in Rhode Island coastal waters and Point Judith Pond. Mar Environ Res 52:445-461. https://doi.org/10.1016/S0141-1136(01)00100-3

Ritz C, Baty F, Streibig JC, Gerhard D (2015) Dose-response analysis using R. PLOS One 10(12):e0146021. https://doi.org/10.1371/ journal.pone.0146021

Russom CL, Bradbury SP, Broderius SJ, Hammermeister DE, Drummond RA (1997) Predicting modes of toxic action from chemical structure: Acute toxicity in the fathead minnow (Pimephales promelas). Environ Toxicol Chem 16:948-967. https://doi.org/ $10.1002 /$ etc. 5620160514

Segner H, Baumann L (2015) What constitutes a model organism in ecotoxicology? Integr Environ Assess Manag 12:199-200. https:// doi.org/10.1002/ieam.1734

Simmons DBD, Benskin JP, Cosgrove JR, Duncker BP, Ekman DR, Martyniuk CJ, Sherry JP (2015) Omics for aquatic ecotoxicology: control of extraneous variability to enhance the analysis of environmental effects. Environ Toxicol Chem 34:1693-1704. https:// doi.org/10.1002/etc.3002

Singer MM, Aurand D, Bragin GE, Clark JR, Coelho GM, Sowby ML, Tjeerdema RS (2000) Standardization of the preparation and quantitation of water-accommodated fractions of petroleum for toxicity testing. Mar Pollut Bull 40:1007-1016. https://doi.org/ 10.1016/S0025-326X(00)00045-X

Sprague JB, McLeese DW (1968) Toxicity of kraft pulp mill effluent for larval and adult lobsters, and juvenile salmon. Water Res 2:753-760. https://doi.org/10.1016/0043-1354(68)90009-2

Tracey M, Nelson K, Hedgecock D, Shleser R, Pressick M (1975) Biochemical genetics of lobsters: genetic variation and the structure of American lobster (Homarus americanus) populations. J Fish Res Board Canada 32(11):2091-2101. https://doi.org/10.1139/ f75-247

USEPA (2016) Ecological effects test guidelines: OSCPP 850.1010: aquatic invertebrate acute toxicity test, freshwater daphnids. Prepared by the office of chemical safety and pollution prevention (7101), Washington, DC, Report EPA 712-C-16-013

USEPA. 2019. ECOTOX User guide: ECOTOXicology knowledgebase system. Version 5.3. Available: http:/www.epa.gov/ecotox/

USEPA. 2021. U.S. Environmental protection agency national contingency plan product schedule. https://www.epa.gov/system/files/ documents/2021-12/ps_dec21_0.pdf

Venosa AD, King DW, Sorial GA (2002) The baffled flask test for dispersant effectiveness: a round robin evaluation of reproducibility and repeatability. Spill Sci Technol Bull 7:299-308. https://doi. org/10.1016/S1353-2561(02)00072-5

Wells PG, Sprague JB (1976) Effects of crude oil on American lobster (Homarus americanus) larvae in the laboratory. J Fish Res Board Canada 33(7):1604-1614. https://doi.org/10.1139/f76-200 